\title{
CORPORATE FED MICROSTRIP ANTENNA ARRAY WITH ENHANCED BANDWIDTH
}

\author{
K. PRAHLADA RAO*, R. M. VANI**, Prabhakar HUNAGUND* \\ *Department of PG Studies and Research in Applied Electronics, Gulbarga University, Gulbarga, Karnataka, India \\ e-mail: pra_kaluri@rediffmail.com,prahladielts@yahoo.co.in \\ ${ }^{* *}$ University Science Instrumentation Centre, Gulbarga University, Gulbarga, Karnataka, India \\ e-mail: pra.shr123@gmail.com
}

\begin{abstract}
The paper throws light on the potentiality of electromagnetic band gap structure and defective ground structure in ameliorating the performance of four element microstrip antenna array. Plus shape patch type electromagnetic band gap structure and rotated dumb bell defective ground structure are employed. The proposed antenna array has bandwidth and gain equal to $54.54 \%$ and 12.77 $d B$ respectively. Virtual size reduction of $26.58 \%$ is also produced. The interference level is improved with reduction in mutual coupling value from $-17.83 \mathrm{~dB}$ to $-25.13 \mathrm{~dB}$ respectively. Moreover, the proposed microstrip antenna array is also yielding appreciable reduction in back lobe radiation. The dielectric substrate employed is FR-4 glass epoxy. The microstrip antenna arrays are designed using Mentor Graphics IE3D software and measured results are obtained using vector network analyzer.
\end{abstract}

Keywords: Antenna Array, Bandwidth, Defective Ground Structure, Dielectric Substrate, Electromagnetic Band Gap Structure, Mutual Coupling, Radiation Pattern

\section{INTRODUCTION}

An antenna is defined as a device for radiating or receiving electromagnetic waves. It is usually required to concentrate the radiated energy in some directions and suppress it in other directions. [1-2]. In recent years wideband systems and technologies are inspiring many scientists, researchers and academicians. The antenna is a very important component of the wideband systems. In certain applications high gains are desired, which are possible using antenna arrays. During the past few years there is a huge demand for high gain, wideband and compact antennas. Microstrip antennas are low profile antennas with simple structure. A patch antenna consists of a metal piece on top of a dielectric substrate. The whole assembly is mounted on a finite ground plane. One of the main limitations of microstrip antenna arrays is the high values of mutual coupling between the antenna elements. Researchers are facing lot of hardships in controlling the drawback of microstrip antenna arrays. [3-4].

Electromagnetic band gap (EBG) structures are artificial periodic structures which aid in improving the mutual coupling levels of microstrip antenna arrays. They are defined as structures which stop or assist the propagation of electromagnetic waves in certain frequency bands. Defective ground structures (DGS) are structures which are loaded in the ground plane of microstrip antenna arrays. [5].

In [6] Eli Yablonovitch has exhibited that if a three dimensional periodic dielectric structure has an electromagnetic band gap which overlaps the electronic band edge, then spontaneous emission can be rigorously suppressed and also stimulated emission would be absent. There is periodic modulation along the laser axis and therefore a forbidden gap in the electromagnetic dispersion relation. In [7] D. N. Elsheakh et al have discussed the study of EBG structures loaded in the ground plane, their types, and their behaviour in enhancing the performance of two element microstrip patch antenna arrays. The EBG structures employed are of two dimensional in nature and corporate feeding technique is used to feed the antenna array. The performances of square, circular, star, $\mathrm{H}$ and I shape EBG structures are compared. Highest bandwidth of $5.1 \%$ has been achieved using $\mathrm{H}$ shape EBG structure. Least amount of mutual coupling (S21) of $-30 \mathrm{~dB}$ and highest gain of $13.75 \mathrm{~dB}$ have been obtained in the case of Star EBG structure. In [8] Vani H. R et al have designed a novel microstrip antenna array with split ring resonator metamaterial loaded in the ground plane. A single layer of split ring resonator is placed around the patch. The $1 \mathrm{~mm}$ gap in the ring gives capacitive effect to split ring resonator. The resonant frequency of patch 1 surrounded by split ring resonator is shifted from 6.8 to $5.5 \mathrm{GHz}$ with a bandwidth of $21.2 \%$. The resonant frequency of patch 2 is shifted from 6.8 to $6.4 \mathrm{GHz}$ with a bandwidth of $6.25 \%$. The coupling between the patches separated by $7 \mathrm{~mm}$ is decreased by 10 $\mathrm{dB}$ in the frequency range 6 to $7.5 \mathrm{GHz}$. When a slot of dimensions of $3.5 \mathrm{~mm} \times 0.3 \mathrm{~mm}$ is placed on patch 1 , the resonant frequency is shifted to $6 \mathrm{GHz}$. Hence miniaturizations of 42 and $27.5 \%$ of patch 1 and patch 2 are produced. In [9] Hassan Elesway et al have designed and fabricated single, two and four element linear microstrip antenna arrays (E shape) using corporate feeding technique. Two parallel slots are cut to perturb the surface current path and enhance the bandwidth. The inter element spacing is $13.6 \mathrm{~mm}$. The directivities of single, two and four element antenna arrays are 7,9 and $12 \mathrm{dBi}$ respectively. The corresponding maximum achievable gains are equal to $5,7.5$ and $11 \mathrm{dBi}$ respectively. Bandwidths obtained are equal to 8,11 and $16 \%$ respectively. The maximum values of antenna and radiation efficiencies are 80 and $88 \%$. In [10] Ali Hanafiah Rambe et al have improved the performance of microstrip antenna using a stub connected to the microstrip feed line. After the introduction of the stub, the return loss is improved by $139 \%$. The values of bandwidths without and with stub are equal to 62.1 and $70.8 \mathrm{MHz}$ respectively for VSWR $\leq 2$. Additionally, there is $2 \%$ increment in the value of gain. In [11] $\mathrm{H}$. Errifi et al have compared the performance of microstrip antenna array using series, corporate and series - corporate feed methods. 
The dielectric substrate employed is RT - Duroid. Microstrip antenna arrays consisting of two, four and eight elements have been designed. The distance between the adjacent antenna elements is $\lambda / 2$. In the case of two element antenna array, corporate feeding method is the best method as it is producing highest gain and directivity of 9.93 and $10.19 \mathrm{~dB}$ respectively. In the case of four element antenna array, corporate feeding method is the best method as it is producing highest gain and directivity of 12.85 and 13.18 $\mathrm{dB}$ respectively. In the case of eight element antenna array, series - corporate feeding method is the best method as it is producing highest gain and directivity of 14.13 and 14.51 dB respectively. In [12] Shruti Dhamankar et al have discussed the different techniques employed for mutual coupling reduction in microstrip antenna arrays. These are using EBG structures, split ring resonators, EBG - split ring resonators and DGS. Using EBG and split ring resonator between two radiating elements, reduces the mutual coupling more compared to other techniques. The mutual coupling is reduced to more than $42 \mathrm{~dB}$ and side lobes by 6 $\mathrm{dB}$. The proposed antenna with spiral resonator has $5.5 \mathrm{~dB}$ reduction in mutual coupling. A $36 \mathrm{~dB}$ reduction in mutual coupling is achieved using DGS. In [13] F. Benikhlef et al have exhibited the reduction of mutual coupling using mushroom like EBG structure on the surface of two element microstrip antenna array. Initially the size of the EBG cells is varied. With the dimensions of unit cells as $3.5 \mathrm{~mm} \times 3.5 \mathrm{~mm}$ and periodicity as $1 \mathrm{~mm}$, mutual coupling is reduced from -32.07 to $-45.72 \mathrm{~dB}$. For the same dimensions of unit cells the periodicity of unit cells is varied. For periodicity of $0.8 \mathrm{~mm}$, best reduction in mutual coupling to $-41.39 \mathrm{~dB}$ is obtained. The same process is repeated with square Koch fractal as radiating patch. The separation between the patches is $22.5 \mathrm{~mm}$. Highest reduction in mutual coupling is observed with one row of EBG equal to $-51.2 \mathrm{~dB}$. Good amount of gain of $7.4 \mathrm{~dB}$ is also obtained. In [14] Sandhya Bhavsar et al have discussed the various types and their behaviour in enhancing the performance characteristics of microstrip antennas. It is found that EBG structures can alleviate the effect of surface wave radiation and thereby decreasing the mutual coupling between the antenna elements. The effect of EBG structures on other parameters like antenna gain, radiation pattern, bandwidth and beam width is also demonstrated. In [15] Mohammad Naser - Moghadasi et al have designed $2 \times 5$ EBG structure to reduce mutual coupling between patch antennas of MIMO array. Two microstrip patch antennas are designed for resonance at 5.28 GHz. The conventional MIMO array is fed by coaxial feed and bandwidth is equal to $3 \%$. The EBG structure is inserted between the two patch antennas and on the surface. Mutual coupling values without and with EBG structure are -22 and $-43 \mathrm{~dB}$ respectively. By increasing the gap between the unit cells of EBG structure, the resonant frequency of proposed MIMO array is reduced. A gain value of $6.86 \mathrm{dBi}$ is also produced. Moreover the EBG structure has reduced antenna current from $8.5 \mathrm{~A} / \mathrm{m}$ to $3.9 \mathrm{~A} / \mathrm{m}$, so the coupling is reduced by $50 \%$. However the antenna efficiency is reduced from 65 to $53 \%$. In [16] Duong Thi Thanh Tu et al have designed dual band MIMO antenna system with enhanced isolation. Using a double rectangular DGS, the antenna is resonating at 2.6 and $5.7 \mathrm{GHz}$ with bandwidths of 5.7 and $4.3 \%$ respectively. The proposed antenna is having high isolation which is stable and around $-20 \mathrm{~dB}$ over all frequencies. At $2.6 \mathrm{GHz}$, gain and radiation efficiency are $2.63 \mathrm{~dB}$ and $59 \%$. The corresponding values at $5.7 \mathrm{GHz}$ are $1.6 \mathrm{~dB}$ and $39.8 \%$. MIMO antenna with double side EBG structure is reducing mutual coupling from -20 to $-40 \mathrm{~dB}$. At $2.6 \mathrm{GHz}$ the antenna gain and radiation efficiency are improved to $4.25 \mathrm{~dB}$ and $68.7 \%$. At $5.7 \mathrm{GHz}$, the antenna gain is increased to $1.76 \mathrm{~dB}$ and radiation efficiency to $39.8 \%$. In [17] Zulkifli et al have employed dumbbell shaped DGS on the opposite side of the feed line. The dielectric material used has a dielectric constant of 2.2 and loss tangent of 0.0009 . The antenna has two substrate layers with electromagnetic coupling feeding technique. The upper substrate layer consists of two element patch antenna with two $U$ shape and $\mathrm{S}$ shape patches. The lower substrate layer consists of four dumbbell slots inserted in the ground plane. Multiband characteristics with three resonant frequencies are obtained. Bandwidths without and with DGS are almost same. However with the improvement of return loss provides an indication of increase of antenna efficiency. At $2.3 \mathrm{GHz}$, a decrease in mutual coupling of 2 to $5 \mathrm{~dB}$, at 3.3 $\mathrm{GHz}$, a decrease in mutual coupling of 0.6 to $3.3 \mathrm{~dB}$ and at $5.8 \mathrm{GHz}$, a decrease in mutual coupling to $2.9 \mathrm{~dB}$ are obtained. For 2.3, 3.3 and $5.8 \mathrm{GHz}$ bands the gain enhancements to $2.4,2.4$ and $3.3 \mathrm{~dB}$ are achieved. In [18] M. Tecpoyotl - Torres et al have implemented three types of DGS for single element and antenna array of 5 and 9 patches. Using first DGS, the single element has return loss and gain equal to $-21.44 \mathrm{~dB}$ and $-0.742 \mathrm{~dB}$ at the resonant frequency of $2.42 \mathrm{GHz}$. For the antenna array based on five patches, return loss and gain are equal to $-17.6 \mathrm{~dB}$ and 4.9 $\mathrm{dB}$ respectively. Using nine patches the corresponding values are $-12 \mathrm{~dB}$ and $5.19 \mathrm{~dB}$. The nine patch antenna array with second DGS produces enhanced gain of $7.01 \mathrm{~dB}$. Finally with third DGS, a healthy gain of $15.33 \mathrm{~dB}$ is obtained along with a return loss of $-23.24 \mathrm{~dB}$. In [19] K. $\mathrm{S}$. Ahmad et al have proposed the design of planar array antenna using I shaped DGS inserted between the patches. It is observed that the resonant frequency of the antenna reduces from 11.22 to $8.25 \mathrm{GHz}$, as the dimensions of DGS are varied. Significant effect on steering of the main beam is observed by changing the dimensions of the DGS. The maximum directivity produced is $6.32 \mathrm{dBi}$. The influence of DGS slot is also visible in reducing the side lobes. In [20] Otman Oulhaj et al have presented an improved method of size reduction with circular polarization using dumbbell shaped DGS. The DGS is etched in the ground plane below the microstrip line. When the DGS is introduced, the resonant frequency of the antenna array is shifted from 10 to $7.5 \mathrm{GHz}$, thus producing a miniaturization of $43.75 \%$. At $7.5 \mathrm{GHz}$ the gain is equal to $8.99 \mathrm{~dB}$. In the proposed antenna array, the current density is more concentrated along the DGS in the ground plane and structure array elements on the top face. In [21] R. A. Pandhare et al have employed U shaped dumbbell DGS to shift the resonant frequency of the microstrip antenna array from 5.2 to 3.8 $\mathrm{GHz}$ to obtain size reduction of $45 \%$. A healthy return loss of $-29 \mathrm{~dB}$ is obtained at the resonant frequency of $3.8 \mathrm{GHz}$. However the gain of the antenna is reduced to $5.9 \mathrm{~dB}$. The decrease in gain is due to the increase of lateral and longitudinal radiations due to the propagation of surface waves. The designed antenna array is useful for WiMax 
application. In [22] Ali Farahbakhsh et al have designed a microstrip antenna array in which the slot is of polygon type and shape is obtained by using an enhanced genetic algorithm. The patches are fed by proximity coupled feeding method. The reflection and coupling of the proposed antenna are 3 and $4 \mathrm{~dB}$ respectively. The gain of the antenna with DGS is improved. The dip in the gain graph shows that the radiation pattern of the antenna is dependent on frequency and the directivity of the antenna is decreased. The E- plane coupling of the array antenna is $11 \mathrm{~dB}$ better than that without DGS. However the back lobe level is increased in array antenna with DGS slot and is due to ground slots. In [23] Susanta Kumar Parui et al have investigated the effect of two $U$ shaped slots connected by a thin transverse slot placed in the ground plane of microstrip antenna. The simulated S parameters of DGS depict one pole low pass filter characteristics with an attenuation pole at $8.5 \mathrm{GHz}$ and $3 \mathrm{~dB}$ cut off frequency at 3 GHz. Two units of DGS when considered provide a sharpness factor of $15 \mathrm{~dB} / \mathrm{GHz}$. A maximum attenuation of $33 \mathrm{~dB}$ is also obtained. Also as the width of the transverse slot is decreased, the stop band centre frequency also decreases due to the increment of the lumped capacitor. Additionally, as the separation between the DGS units increases, the $3 \mathrm{~dB}$ cut off frequency and stop band centre frequency decrease due to the increase of lumped inductance. The values of mutual coupling are also decreased.

The newness in this paper is that EBG structures are employed on the surface instead in the ground plane. Additionally, the combined effect of EBG and DGS structures on microstrip antenna arrays is observed. Comparing the published research results with the research results in this paper, highest bandwidth of $54.54 \%$ is obtained in this paper. Moreover better reduction in back lobe radiation is also produced in this paper compared to other published results.

\section{CONVENTIONAL MICROSTRIP ANTENNA ARRAY}

The two element conventional microstrip antenna array (TCMAA) consists of two identical rectangular radiating elements designed at $6 \mathrm{GHz}$. The dielectric substrate employed is FR-4 glass epoxy which has a dielectric constant of 4.2 and loss tangent of 0.0245 . The substrate height is equal to $1.6 \mathrm{~mm}$. The dimensions of the finite ground plane to design TCMAA are $115.8 \mathrm{~mm} \times 62.7 \mathrm{~mm}$. The two elements of TCMAA are separated by a distance of $\lambda / 4$, where $\lambda$ is the wavelength calculated at the design frequency of $6 \mathrm{GHz}$. The feeding method employed to excite TCMAA is corporate feeding method. The dimensions of each of the radiating patches are $15.73 \mathrm{~mm}$ $\times 11.76 \mathrm{~mm}$. The schematic of TCMAA is depicted in Fig. 1 and is employed to determine the return loss of CMAA. Return loss is designated by the S-parameter $\mathrm{S}_{11}$.

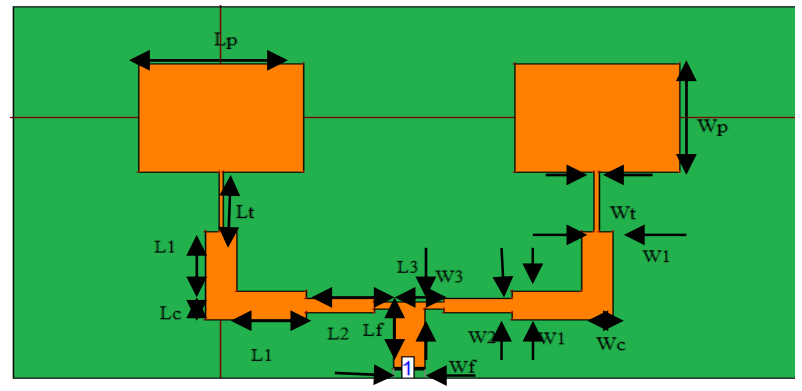

Fig. 1 CMAA

All the dimension values of the parts of CMAA are presented in Table 1.

Table 1 Dimensions and values of CMAA

\section{Dimension}

Length of the patch (Lp)

Width of the patch (Wp)

Length of the quarter wave transformer (Lt)

Width of the quarter wave transformer (Wt)

Length of the $50 \Omega$ line (L1)

Width of the $50 \Omega$ line (W1)

Length of the coupler (Lc)

Width of the coupler (Wc)

Length of the $70 \Omega$ line (L2)

Width of the $70 \Omega$ line (W2)

Length of the $100 \Omega$ line (L3)

Width of the $100 \Omega$ line (W3)

Length of the feed line (Lf)

Width of the feed line (Wf)
Value
(mm)
15.73
11.76
6.47
0.47
6.52
3.05
3.05
3.05
6.54
1.62
6.56
0.70
6.52
3.05

The two radiating patches of TCMAA are fed separately as shown in Fig. 2 to measure the mutual coupling between the two radiating patches. The two radiating patches are separated by the same distance as that maintained in Fig. 1. Moreover the two radiating patches are assumed to be excited with the same amount of power. Mutual coupling is designated by the $\mathrm{S}$-parameter $\mathrm{S}_{21}$.

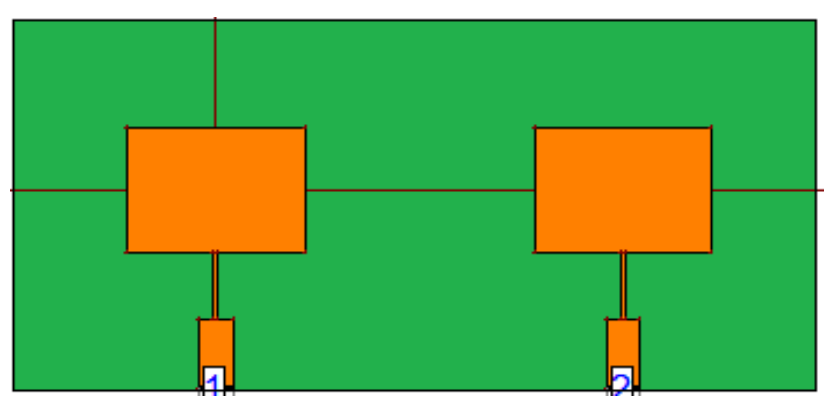

Fig. 2 Setup of CMAA for mutual coupling measurement 


\section{EBG AND DGS STRUCTURES}

The EBG structure employed in the design consists of a matrix of 3 rows and 2 columns of plus shape patch type EBG structure. The unit cell of the EBG structure employed is depicted in Fig. 3.

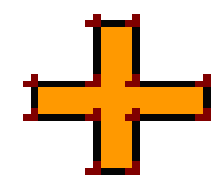

Fig. 3 Unit cell of EBG structure

The unit cell of the EBG structure depicted in Fig. 4 consists of two rectangles intersecting each other at right angles and at their centres. The dimensions of each of the rectangles are $5 \mathrm{~mm}$ and $1 \mathrm{~mm}$ respectively. The plus shape patch type EBG structure is shown in Fig. 4.

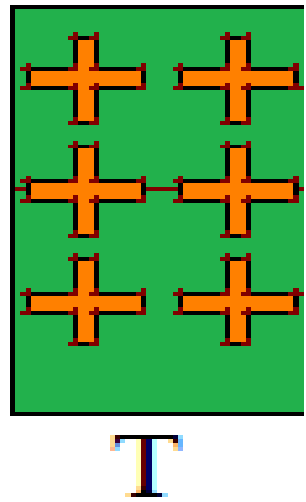

Fig. 4 EBG structure

In Fig. 4, the unit cells of the EBG structure are seperated by a distance of $\mathrm{T}=1.5 \mathrm{~mm}$ along the $\mathrm{x}$-axis and y-axis.

The DGS consists of a rotated dumbbell shape structure. The dumbbell structure is rotated by $90^{\circ}$ from its usual horizontal position. Fig. 5 shows the schematic of DGS structure. It consists of two squares which are joined at the centres of one of their sides by a rectangle. The dimensions of each of the squares of the DGS structure are $5 \mathrm{~mm} \times 5$ $\mathrm{mm}$ respectively. The length and breadth of each of the rectangles of DGS structure are $6 \mathrm{~mm}$ and $2 \mathrm{~mm}$ respectively.

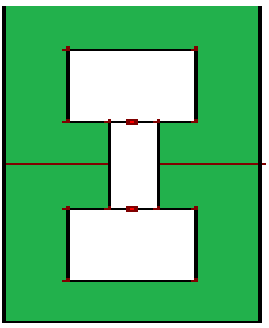

Fig. 5 Schematic of DGS

\section{PROPOSED MICROSTRIP ANTENNA ARRAY}

The design of two element proposed microstrip antenna array (TPMAA) is obtained by modifying the TCMAA. TPMAA has plus shape patch type EBG structure on its surface and rotated dumbbell DGS in its ground plane. The ground plane dimensions of TCMAA and TPMAA are same. In addition, the plus shape patch type EBG structure and rotated dumbbell DGS are loaded in between the radiating patches. The schematic of TPMAA is depicted Fig. 6. The schematic in Fig. 6 is used to measure the return loss characteristics of TPMAA.

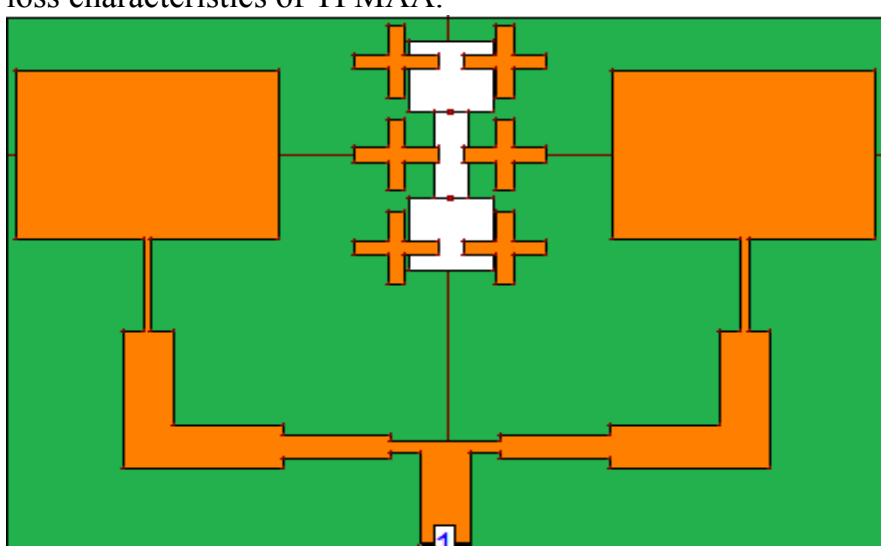

Fig. 6 PMAA

Fig. 7 depicts the schematic employed to determine the effect of EBG and DGS structures on the mutual coupling coefficients. It consists of setup of elements of TPMAA which are fed separately.

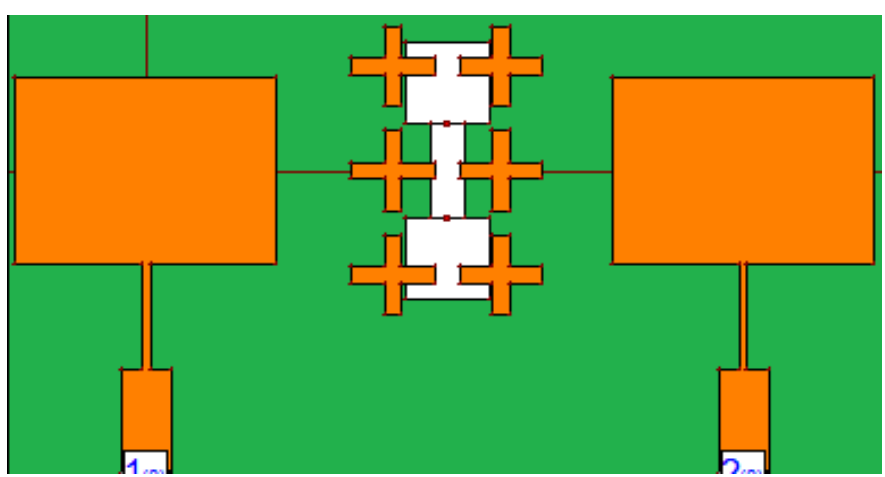

Fig. 7 Setup of PMAA for mutual coupling measurement

Figs. 8, 9, 10 and 11 depict the photographs of fabricated antennas TCMAA and TPMAA.

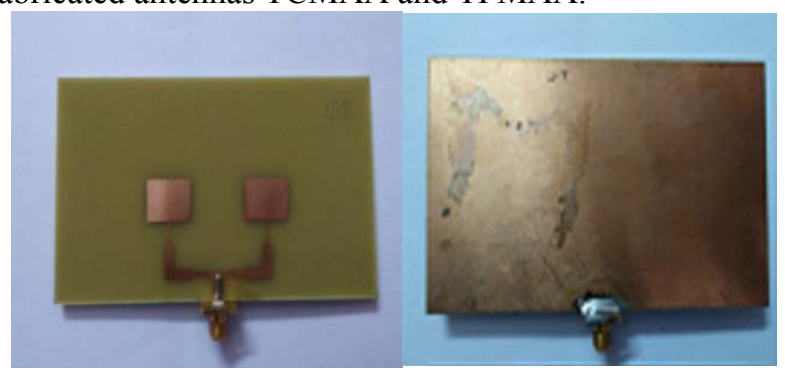

Fig. 8 Photograph of CMAA (a) Front view (b) Back view 

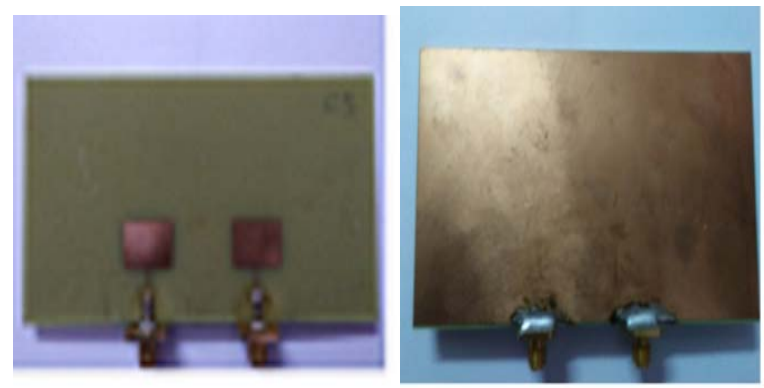

Fig. 9 Photograph of setup of CMAA for mutual coupling measurement

(a) Front view (b) Back view

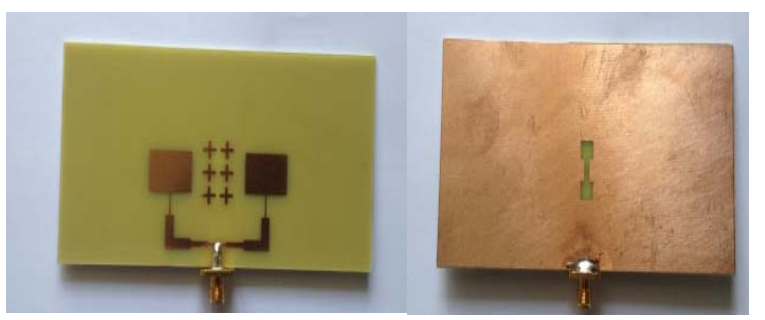

Fig. 10 Photograph of PMAA

(a) Front view (b) Back view

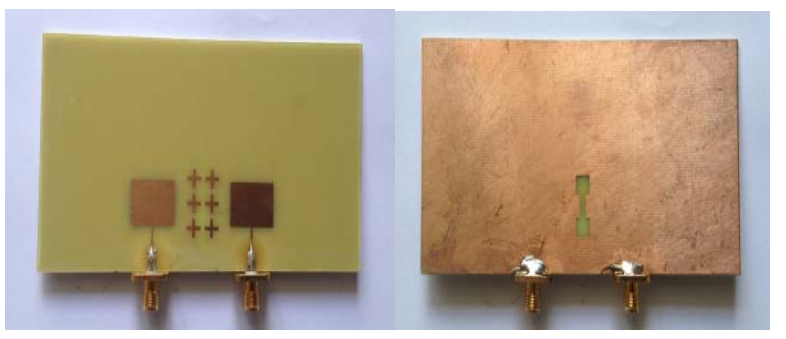

Fig. 11 Photograph of setup of PMAA for mutual coupling measurement

(a) Front view (b) Back view

\section{RESULTS}

The measured results of the fabricated antennas TCMAA and TPMAA are obtained using vector network analyzer. Fig. 12 depicts the graph of measured results of return loss and mutual coupling versus frequency of TCMAA. The frequency range over which the measured results are taken is $1-7 \mathrm{GHz}$.

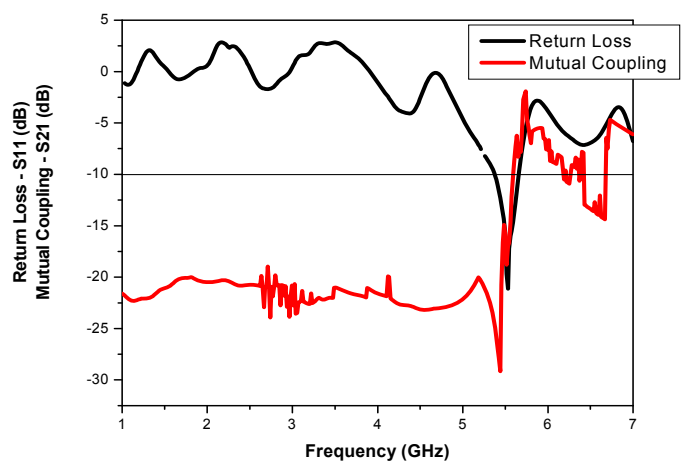

Fig. 12 Graph of return loss and mutual coupling versus frequency of CMAA
Fig. 12 depicts that TCMAA is resonating at the fundamental frequency of $5.53 \mathrm{GHz}$ with a return loss of $21.23 \mathrm{~dB}$. TCMAA is producing a bandwidth of $130 \mathrm{GHz}$. Bandwidth (\%) is determined by using equation (1)

$\frac{\text { Bandwidth }}{\text { Resonant frequency }} \times 100 \%$

Hence bandwidth (\%) of TCMAA is equal to $2.35 \%$. The mutual coupling parameter measured is $\mathrm{S}_{21}$. From Figure 12 the value of the mutual coupling parameter at the resonant frequency of $5.53 \mathrm{GHz}$ is $-17.83 \mathrm{~dB}$. The mutual coupling value is high as it is greater than $-20 \mathrm{~dB}$. Furthermore Figure 12 also shows that the plots of return loss and mutual coupling are crossing each other at the resonant frequency of $5.53 \mathrm{GHz}$. This implies there is huge amount of interference between the transmitting element 1 and the receiving element 2 of TCMAA. Therefore there is improper transmission and reception of electromagnetic signals in TCMAA.

Fig. 13 shows the graph of measured return loss and mutual coupling characteristics versus frequency of TPMAA.

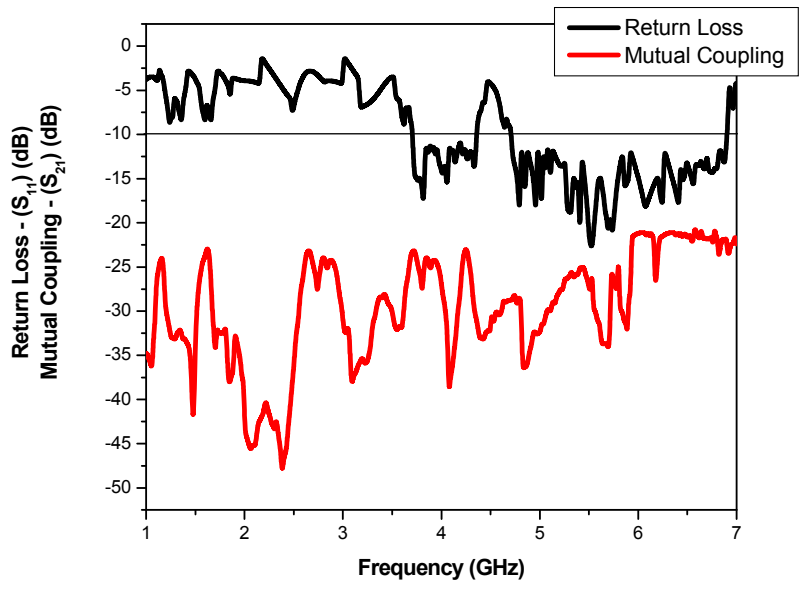

Fig. 13 Graph of return loss and mutual coupling versus frequency of PMAA

From Fig. 13 we see that TPMAA is resonating at dual bands i.e. at 3.81 and $5.53 \mathrm{GHz}$ respectively. FPMAA is producing bandwidths of 625 and $2110 \mathrm{MHz}$ at these two resonant frequencies. Thus TPMAA is producing an overall bandwidth of $54.54 \%$, which is greater than $2.35 \%$ produced by its counterpart i.e. TCMAA. The value of mutual coupling obtained at the resonant frequency of 5.53 $\mathrm{GHz}$ is equal to $-25.13 \mathrm{~dB}$. The value of mutual coupling parameter is reduced compared to that obtained by TCMAA. Also, the graphs of return loss and mutual coupling of TPMAA are not overlapping with each other at the resonant frequency of $5.53 \mathrm{GHz}$. This confirms the decreased interference level in TPMAA compared to that in TCMAA. Hence TPMAA is a better performer than TCMAA in terms of parameters bandwidth (\%) and mutual coupling.

Figs. 12 and 13 depict that TCMAA and TPMAA are producing fundamental resonant frequencies of 5.53 and $3.81 \mathrm{GHz}$ respectively. TPMAA is thus resonating at lower fundamental frequency compared to TCMAA. This accounts to virtual size reduction. To calculate the virtual size reduction (\%) produced by TPMAA equation (2) is employed. 


$$
\left(\frac{f 1-f 2}{f 1}\right) \times 100
$$

In equation (2) $f_{1}$ and $f_{2}$ are the fundamental resonant frequencies of TCMAA and TPMAA. Substituting the relevant parameters in equation (2), the virtual size reduction $(\%)$ produced by TPMAA is calculated as equal to $26.58 \%$.

The gains of the antennas TCMAA and TPMAA are determined by using the equation (3)

$$
G=20 \log _{10}\left(\frac{4 \pi R}{\lambda}\right)+10 \log _{10} \frac{P r}{P t}-G t
$$

where: $\mathrm{Pt}$ - transmitted power, $\mathrm{Pr}$ - received power, $\mathrm{R}$ distance between the transmitting and the receiving antennas, $\lambda$ - wavelength at the resonant frequency of 5.53 $\mathrm{GHz}, \mathrm{Gt}$ - gain of the transmitting antenna.

$\mathrm{Gt}$ is given by the equation (4)

$$
\begin{aligned}
& G t=10 \log _{10} G s \\
& G s=\frac{2 \pi a b}{\lambda^{2}}
\end{aligned}
$$

where $a$ and $b$ are the length and width of the standard pyramidal horn antenna used as the transmitting antenna. The receiving antenna is the antenna under test i.e. TCMAA and TPMAA respectively. The dimensions a and $\mathrm{b}$ are equal to 24 and $14 \mathrm{~cm}$ respectively. The distance between the transmitting antenna (standard pyramidal horn antenna) and the receiving antenna is given by the equation (6)

$$
R \geq \frac{2 D^{2}}{\lambda}
$$

where $\mathrm{D}$ is the larger dimension of the transmitting antenna. The dimension $\mathrm{D}$ is equal to $24 \mathrm{~cm}$. The value of $\mathrm{R}$ is equal to $71.86 \mathrm{~m}$.

Initially considering TCMAA as the receiving antenna, the transmitted and received powers of TCMAA are equal to $8.7 \mu \mathrm{W}$ and $8.8 \mathrm{nW}$ respectively. Substituting the corresponding parameter values in equation (3), TCMAA is producing gain equal to $5.069 \mathrm{~dB}$. Considering TPMAA as the receiving antenna, the measured values of transmitted and received powers are equal to $8.7 \mu \mathrm{W}$ and $0.0489 \mu \mathrm{W}$ respectively. Substituting the corresponding parameter values in equation (3), the value of gain of TPMAA is equal to $12.77 \mathrm{~dB}$. Thus TPMAA is producing enhanced gain of $12.77 \mathrm{~dB}$ as compared to $5.069 \mathrm{~dB}$ produced by TCMAA. Hence TPMAA is a better antenna than TCMAA in terms of gain parameter.

The radiation pattern of an antenna is obtained by plotting the values of electromagnetic power at various angles from $0^{0}$ to $360^{\circ}$ on a polar plot. The forward power is measured at the angle of $90^{\circ}$ and back lobe radiation at the angle of $360^{\circ}$. The radiation plots of the conventional antenna array TCMAA and the proposed antenna array TPMAA are depicted in Fig. 14.

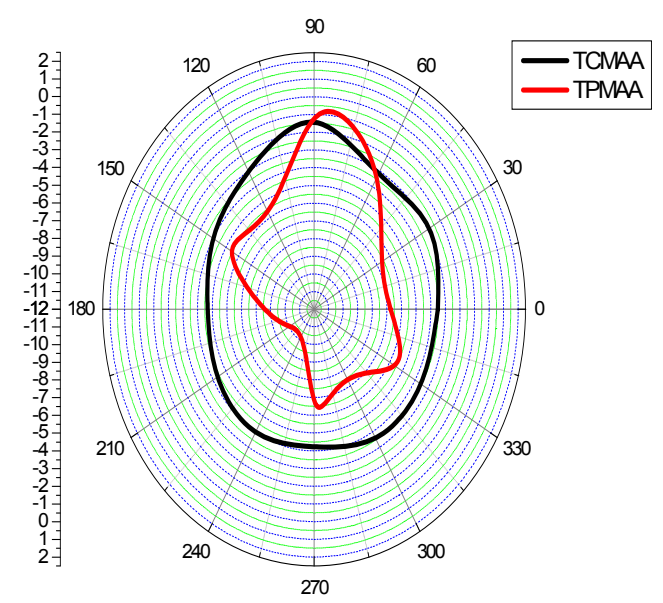

Fig. 14 Plot of radiation patterns of CMAA and PMAA

The radiation pattern of TCMAA depicts that TCMAA is radiating a forward power of $-1.31 \mathrm{~dB}$ and a back lobe radiation of $-4.18 \mathrm{~dB}$ respectively. In the presence of rotated dumbbell shape DGS and plus shape patch type EBG structure, TPMAA is producing increased forward power of $-1 \mathrm{~dB}$ and reduced backward power of $-7 \mathrm{~dB}$ respectively. The front to back ratio (FBR) parameter is calculated by subtracting the power radiated in the backward direction from the power radiated in the forward direction. Therefore, the FBR values of TCMAA and TPMAA are equal to 2.87 and $6 \mathrm{~dB}$ respectively. Comparing TCMAA and TPMAA in terms of forward power, backward power and FBR values, TPMAA is radiating enhanced power in the desired direction and decreased power in the undesired direction. Hence, TPMAA is a better performer than TCMAA as far as forward and backward powers are concerned. The greater value of FBR of TPMAA than that produced by TCMAA indicates that TPMAA is a better radiator than TCMAA in terms of FBR.

\section{CONCLUSIONS}

The conventional and proposed microstrip antenna arrays have been successfully designed, fabricated and tested experimentally. A healthy bandwidth of $54.54 \%$ and appreciable reduction in mutual coupling are produced, indicating the ability of plus shape patch type electromagnetic band gap structure and rotated dumbbell defective ground structure. Additionally, the gain value is enhanced to $12.77 \mathrm{~dB}$. The better performance of proposed microstrip antenna array is demonstrated by a good value of virtual size reduction and notable decrease in back lobe radiation. 


\section{REFERENCES}

[1] CONSTANTINE BALANIS, A.: Antenna Theory, Analysis and Design, 2d ed. New Jersey: John Wiley \& Sons Inc, 1997.

[2] BAHL, I. J. - BHARTIA, P.: Microstrip Antennas, Artech House, 1980.

[3] PREINHOLD, LUDWIG. - PAVEL BRETCHKO.: RF Circuit Design: Theory and Applications, $2 \mathrm{~d}$ ed. New Jersey: Pearson, 2009.

[4] MATTHAEI, G. L. - YOUNG, L. - JONES, E. M.T.: Microwave Filters, Impedance Matching Networks and Coupling Structures, New Jersey: Artech House, 1980.

[5] FAN, YANG. - YAHYA RAHMAT, SAMII.: Electromagnetic Band Gap Structures in Antenna Engineering, Cambridge University Press, 2009.

[6] ELI YABLANOVITCH.: Inhibited spontaneous emission in solid state physics and electronics, Physical Review Letters, vol. 58, no. 20, pp. 20592062, May. 1987.

[7] ELSHEAKH, D. N. - ISKANDER, M. F. ABDALLAH, E. A. - ELSADEK, E. A.: Microstrip array antenna with new 2D - electromagnetic band gap structure shapes to reduce harmonics and mutual coupling, Progress in Electromagnetic Research C, vol. 12, pp. 203-213, 2010.

[8] VANI, H. R. - PARAMESHA. - GOUTHAM, M. G.: A miniaturized microstrip patch antenna array with enhanced bandwidth and reduced mutual coupling for wireless application, International Journal of Recent Advances in Engineering \& Technology, vol. 3, no. 9, pp. 105-108, Dec. 2015.

[9] HASSAN, ELESAWYY. - SWELAM, W. ABDALMONEM, FOUDA. - ISMAIL HAFEZ, M.: Design of microstrip array antenna for wireless communication application, IOSR Journal of Engineering, vol. 3, no. 12, pp. 1-7, Dec. 2013.

[10] ALI HANAFIAH, RAMBE. - EDDY, MARLIANTO. - NASRUDDIN, M. N. - FITRI, AMIA.: Optimizing rectangular patch antenna with microstrip line feed using single stub, International Journal of Electronics and Electrical Engineering, vol. 3, no. 6, pp. 416-423, Dec. 2015.

[11] ERRIFI, H. - BAGHDAD, A. - BADRI, A. SAHEL, A.: Design and analysis of directive microstrip patch array antennas with series, corporate and series-corporate feed network, International Journal of Engineering Research \& Technology, vol. 2, no. 12, pp. 1599-1602, Dec. 2013.

[12] SHRUTI, DHAMANKAR. - SNEHAL, LOPES.: Mutual coupling reduction techniques in microstrip patch antennas: a survey, International Research Journal of Engineering and Technology, vol. 3, no. 3, pp. 1064-1069, Mar. 2016.

[13] BENIKHLEF, F. - BOUKLI-HACENE, N.: Mutual coupling reduction in patch antenna arrays using EBG structure, International Journal of Computer Science Issues, vol. 9, no. 4, pp. 265-269, Jul. 2012.

[14] SANDHYA, BHAVSAR. - BHARTI, SINGH.: Electromagnetic band gap structures incorporated in antenna array, International Journal of Computer Technology and Electronics Engineering, vol. 3, special issue, pp. 23-28, Mar-Apr. 2013.

[15] MOHAMMED NASER, MOGHADASI. RAHELE, AHMADIAN. - ZAHRA, MANSOURI. FERDOWS ZARRABI, B. - MARYAM RAHIMI, B.: Compact EBG structures for reduction of mutual coupling in patch antenna MIMO arrays, Progress in Electromagnetics Research C, vol. 53, pp. 145-154, 2014.

[16] DUONG THI THANH, TU. - NGUYEN VAN, HOC. - PHAM DINH, SON. - VU VAN, YEM.: Design and implementation of dual- band MIMO antenna with low mutual coupling using electromagnetic band gap structures for portable equipments, International Journal of Engineering and Technology Innovation, vol. 7, no. 1, pp. 48-60, 2017.

[17] ZULKIFLI, F. Y. - RAHARDJO, R. T. HARTANTO, D.: Mutual coupling reduction using dumbbell defected ground structure for multi band microstrip antenna array, Progress in Electromagnetic Research Letters, vol. 13, pp. 29-40, 2010.

[18] TECPOYOTL-TORRES, M. - VERA DIMAS, J. G. - CASTA-SOTELO, R. - CABELLO-RUIS, R.: Rectangular patch antenna array with defective ground structure for W-Fi, International Journal of Engineering and Innovative Technology, vol. 3, no. 5, pp. 365-371, Nov. 2013.

[19] AHMAD, K. S. - HAMZAH F, S. A. - SEMAN, F. C.: Defected ground structure for beam steering array antenna applications, ARPN Journal of Engineering and Applied Sciences, vol. 10, no. 19, pp. 8653-8658, Oct. 2015.

[20] OTMAN, OULHAJ. - NAIMA TOUHAMI, A. MOHAMED, AGHOUTANE. - ANTONIO, TAZON.: A miniature microstrip patch antenna array with defected ground structure, International Journal of Microwave and Optical Technology, vol. 11, no. 1, pp. 32-39, Jan. 2016.

[21] PANDHARE, R. A. - ZADE, P. L. ABEGAONKAR, M. P.: Miniaturized microstrip patch antenna array at $3.8 \mathrm{GHz}$ for WiMax application, IOSR Journal of Electronics and Communication Engineering, vol. 10, no. 6, pp. 20 24, Nov. 2015.

[22] ALI, FARAHBAKSH. - GHOLAMREZA, MORADI. - SHAHRAM, MOHANNA.: Reduction of mutual coupling in microstrip array antenna using polygonal defected ground structure, AECS Journal, vol. 26, no. 4, pp. 334-339, Apr. 2011.

[23] SUSANTA KUMAR, PARUI. - SANTANU, DAS.: A new defected ground structure for different 
microstrip circuit applications, Radioengineering, vol. 16, no. 1, pp. 16-22, Apr. 2007.

[24] PRAHLADA RAO, K. - VANI, R. M. HUNAGUND, P.V.: Two element microstrip antenna array using square slot EBG structure for C- band applications, International Conference on Innovations in Power and Advanced Computing Technologies, Vellore, INDIA, pp. 1-5, Apr. 2017.

[25] PRAHLADA RAO, K. - VANI R.M. HUNAGUND, P. V..: Multi element microstrip antenna arrays using electromagnetic band gap structures, Helix, vol. 8, no. 5, pp. 3637-3650, 2018.

Received October 4, 2019, accepted, October 21, 2019

\section{BIOGRAPHIES}

K. Prahlada Rao received his M.E from RMIT University, Australia and B.E from Osmania University, India. Currently he is pursuing $\mathrm{Ph}$. D in the field of microwave antennas from the department of Applied Electronics, Gulbarga University, Gulbarga, India $\mathrm{He}$ has research papers in various national and international journals and conferences, which include publications in scopus and web of science indexed publications. His areas of research interests include microstrip patch antennas and arrays, Electromagnetic Band Gap Structures, Defective Ground Structures, nanomaterials.
Vani R. M. received her B.E. in Electrical and Electronics from B.I.E.T, Davangere and $M$. Tech in Industrial Electronics from S.J.C.E. Mysore, Karnataka. She has received her Ph.D in Applied Electronics from Gulbarga University, Gulbarga, India, in the year 2005. She is working as Professor \& Head, University Science Instrumentation Centre, Gulbarga University, Gulbarga. She has more than 100 research publications in national and international reputed journals/Conference proceedings. She has presented many research papers in National/ International conferences in India and abroad. She has guided many Ph.D and M.Phil students. She has conducted several courses, workshops and symposiums for the benefit of university faculty and PG students. Her areas of interest are microwave antennas, compact and broadband antennas, Embedded controllers and Wireless communication. She has completed one UGC major research project.

Prabhakar V. Hunagund, received his M.Sc. and Ph.D. from the Dept. of Applied Electronics, Gulbarga University, Gulbarga, in the year 1982 and 1992 respectively. He is working as professor and chairman of Applied Electronics department, Gulbarga University, Gulbarga. He has more than 125 research publications in national and international reputed journals, more than 100 research publications in national and international symposium/Conferences. He has presented many research papers in National/International conferences in India and abroad. He has guided many $\mathrm{Ph}$. D and $\mathrm{M}$. Phil students. He has completed three major research projects funded by AICTE, DST and UGC New Delhi. 